\title{
Glass fibres: absence of pulmonary hazard in production workers
}

\author{
J. W. HILL, W. S. WHITEHEAD, J. D. CAMERON, \\ and G. A. HEDGECOCK \\ Pilkington Brothers Limited, St. Helens, Lancashire
}

\begin{abstract}
Hill, J. W., Whitehead, W. S., Cameron, J. D., and Hedgecock, G. A. (1973). British Journal of Industrial Medicine, 30, 174-179. Glass fibres: absence of pulmonary hazard in production workers. Seventy fibreglass workers with a mean of 19.85 years in the industry are compared with a control group having no exposure to glass fibre but otherwise matched for age, sex, height, and weight, and residing in the same geographical area.

Comparison was made by radiography, the administration of the modified Medical Research Council Short Questionnaire on Respiratory Symptoms (1960), amplified to include a detailed occupational history, and measurement of peak expiratory flow, $\mathrm{FEV}_{1}$, and FVC.

Statistical analysis showed the control group to be at a slight disadvantage compared to the subject group in respect of complaints of phlegm and FVC. No evidence of any respiratory hazard due to glass fibre is shown.
\end{abstract}

Since their early manufacture in the 1930s, the diameter of glass fibres has reduced from a manufacturing specification of 15 microns (range 6-20) to 7 microns (range $0 \cdot 5-25$ ), and the method of bonding has changed from oils to bitumen to phenolformaldehyde resins, both changes making it possible that a larger amount of respirable dust is evolved during manufacture and processing of the material, and introducing an additional possible hazard of resin sensitization while the uncured material is handled.

The material's siliceous nature and morphological similarity to asbestos fibres, and the resinous nature of the bonding size have all given rise to speculation as to a possible pulmonary hazard, in spite of the fact that glass contains no free silica and is totally different from asbestos in its chemical composition.

\section{Methods}

The present study was designed to allow comparisons to be made between a group of 70 workers with a lengthy exposure to glass fibre and a control group matched for age, sex, height, and weight. The two groups worked in the same town, the controls being drawn from the same geographical area to minimize independent environmental factors. The control group was employed in glass warehouses where there is no significant exposure to dust and where fibreglass was not used.

The subject group had periods of 12 to 24 years' exposure to glass fibre dust in the manufacturing industry with a mean exposure of $19 \cdot 85$ years.

Workers who had been exposed to dust or fumes in previous occupations were excluded from the survey and matching was achieved to 5 or less years of age, 1 inch $(25.4 \mathrm{~mm})$ of height, and $7 \mathrm{lb}$. $(3.2 \mathrm{~kg})$ of weight.

Chest radiographs were done by a standardized high kilovoltage technique using a grid cassette at $5^{\prime} \mathrm{ffd}, 300$ $\mathrm{mA}$ and exposed for $0.02 \mathrm{sec}$, varying $\mathrm{kV}$ between 90 and 100 units. To minimize observer error the whole series of subjects and controls were placed in random order and divided into batches of 20 which were then read independently by two radiologists. Identification was by code only without details of age, weight, etc. The subject series was then reported on as a group by each radiologist, this time with knowledge of age and weight, to discover whether any radiographic trend could be discovered by this additional method.

The possibility of an increased incidence of bronchitis or other chest symptoms was dealt with by the admin- 
istration of the Medical Research Council Short Questionnaire on Respiratory Symptoms (1960), augmented to include a detailed occupational history. The questions were asked in standard form by one person only (W.S.W.), such explanation being given, when required, as to make the meaning of the questions clear.

Lung function was measured by peak expiratory flow using a Wright peak flow meter and the forced expired volume in one second $\left(F E V_{1}\right)$ and forced vital capacity (FVC) using a Vitalograph, in all cases the mean of three values being taken after two practice attempts. It was felt that these investigations would be sufficient to reveal any indication of impairment due to obstructive disorders which might accompany or precede radiographic change, and which might be due to glass fibre acting as either an irritant dust or an allergen. While the phenolformaldehyde resin with which fibreglass is coated is itself a known sensitizer, and its constituents are individually more active than the resin, it is usually held that the polymerization effected by heat-curing removes this property. It was nevertheless deemed necessary to look carefully for signs of bronchospasm in both the pulmonary function examination and in the questionnaire as heat-curing cannot always be guaranteed chemically to have achieved $100 \%$ polymerization or to have completely eliminated the constituent parts.

The major causes of airborne dust in glass fibre insulation production are the manual and automatic handling of products as they are processed by sawing and trimming operations. The environmental survey was, therefore, concentrated on these more severe emissions, exposure to which varies from $30 \%$ to $50 \%$ of the working time.

The general atmosphere at the time of the investigation contained an average number of 0.9 respirable fibres $/ \mathrm{cm}^{3}$, as measured by membrane filters using Casella personal samplers, and a mean of $0.4 \mathrm{mg} / \mathrm{m}^{3}$ as measured gravimetrically. As glass fibre is manufactured to a specified diameter there tends to be a lower proportion of respirable dust as compared with dust containing naturally occurring fibres such as asbestos. The high proportion of heavier fibres accounts for the rapid fall off in both fibre count and gravimetric estimations of dust concentration as between the dust source and the breathing zone of the operator approximately $2 \mathrm{ft}(0.6 \mathrm{~m})$ above it. The presence of a large number of non-respirable fibres in the gravimetric samples also tends to increase such weight disproportionately.

Samples were evaluated by:

(a) counting under the miscroscope, all fibres having an aspect ratio of greater than $3: 1$ and between 5 and 100 microns in length being counted (Hygiene Standards, British Occupational Hygiene Society). This convention has been adopted because of the difficulty of distinguishing fibres morphologically from spherical dust, much below 5 microns. The incidence of counts in this range is very small (see Fig. 2). Two hundred random fields were selected from each exposed filter area and the number of particles per cubic centimetre of air samples was calculated;

(b) gravimetric determination of the total dust on the filters expressed as $\mathrm{mg} / \mathrm{m}^{3}$ of air sampled;

(c) frequency curves for the length and diameter of airborne fibres in generated dust, i.e., dust evolved by air trimming and sawing, and measured at the height of the dust emission, generally bench level at a distance of $2 \mathrm{ft}(0.6 \mathrm{~m})$.

\section{Results}

\section{Dust concentrations}

The concentrations found at the operators' breathing zone and $2 \mathrm{ft}(0.6 \mathrm{~m})$ from the breathing zone are shown in Table 1. The bench level concentrations are considerably higher than those at the breathing zone, indicating a rapid fall off. This is consistent with the presence of a high proportion of heavier particles. The distribution of dust particle sizes is given in Fig. 1 for the fibre diameter and in Fig. 2 for the fibre length. Although measurements are not available for the last 20 years we do not think there has been any material change.

\section{Radiographic findings}

Each film was classified according to the following code:

1 Normal

2 Abnormal A Pneumoconiosis

B Others: a Healed tuberculosis

b Bronchitis and emphysema

c Inflammatory

d Miscellaneous.

The radiologists (S. and W.) gave the same reading for $58 \%$ of subjects. For a further $14.5 \%$ the difference may be due to differing views of normality in the absence of any details of height and weight, and in only $22 \%$ did the diagnostic combination of $1-2 \mathrm{Bb}$ or $1-2 \mathrm{Bc}$ occur. No case of pneumoconiosis was suspected or reported (Table 2).

To find whether there is a significant difference between the fibreglass and control groups only those diagnoses on which the radiologists agree can be considered (Table 3 ).

There is no significant difference between the fibreglass and control groups.

The differences between the radiologists were largely concerned with the definition of normal and the classification of minimal radiological appearances.

The films were then viewed by each radiologist as a series of either glass fibre workers or controls with information of age, etc., but no pattern or trend was discerned by either radiologist as characterizing either group.

Subsequently the films were read independently by J. C. Gilson of the Pneumoconiosis Research Unit at Llandough, the controls and subjects being randomly mixed and read completely blind as far as the identification was concerned. He classified them using the new UICC/Cincinnati classification of the radiographic appearance of pneumoconiosis and noted that there were small differences in the 
TABLE 1

Dust CONCENTRATIONS

(a) OPERATORs' Breathing ZoNe

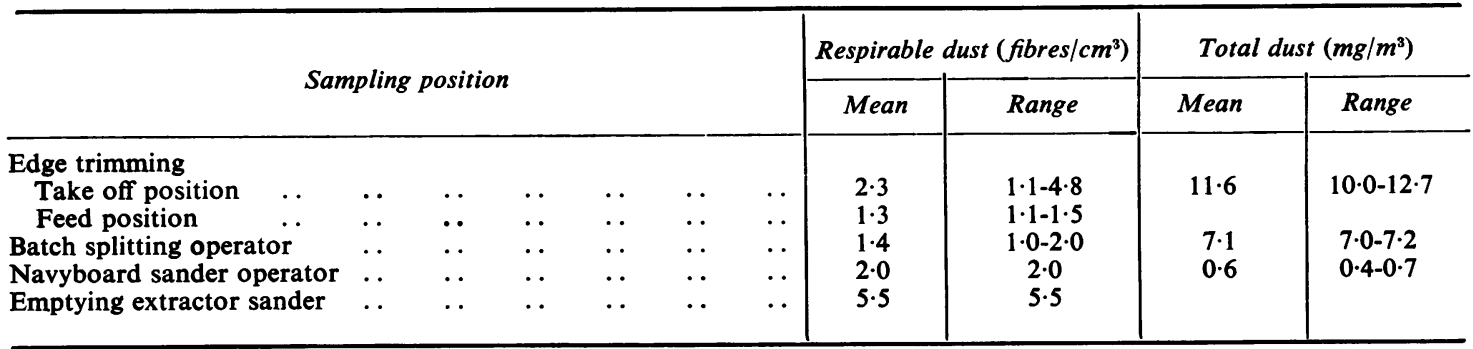

(b) 2 FT From Operators' Breathing ZONE

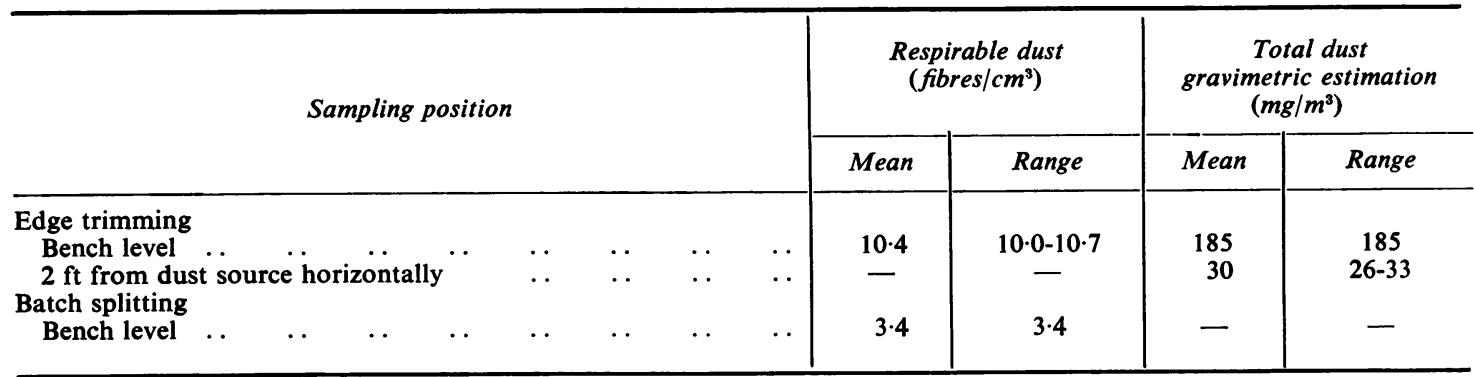

number of films classified into the low categories of types ' $q$ ' (small rounded opacities) and ' $t$ ' (small irregular opacities) in the two groups. There were 16 ' $q$ 's or ' $t$ 's in the glass fibre group and 13 in the controls. He concluded that his readings supported the assessments of the previous two radiologists in that 'there were no significant differences in the radiographic appearances of the two groups'.

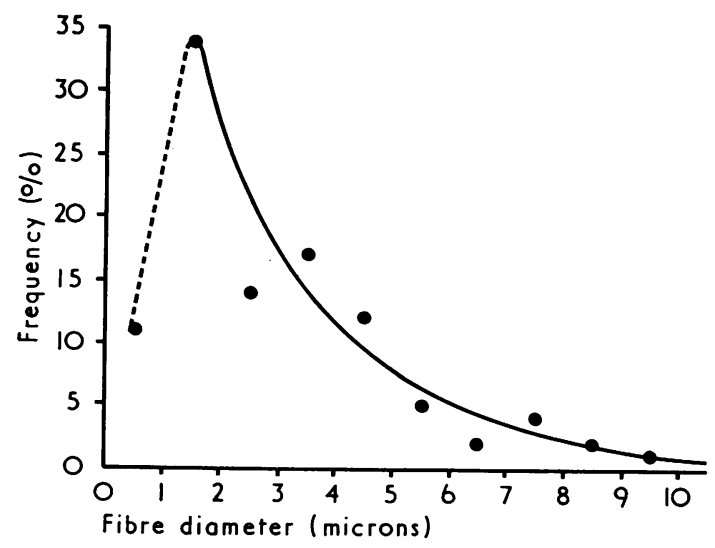

FIG. 1. Distribution of fibrous dust size by diameter (collected at site of emission).

\section{Questionnaire}

Each subject was next considered according to the number of affirmative answers given to the questions under each heading of the modified MRC questionnaire. The two groups were then compared using the Wilcoxon sign test.

There was a significant difference between the groups in respect of reports of phlegm and rashes.

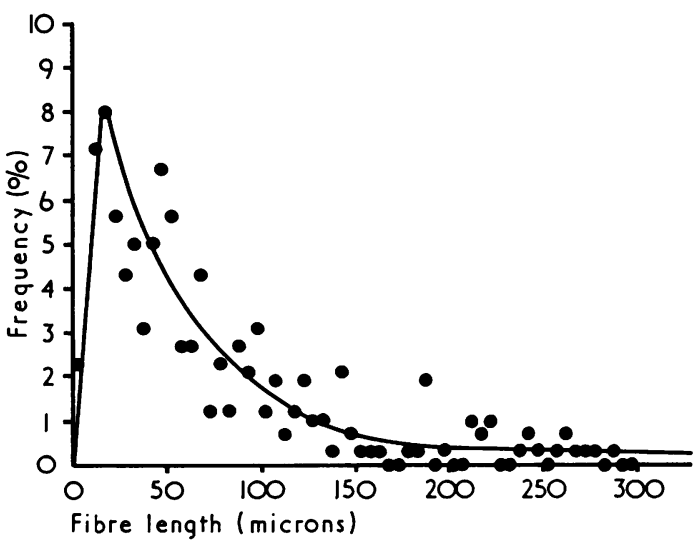

FIG. 2. Distribution of fibrous dust size by length (collected at site of emission). 
TABLE 2

Comparison of X-Ray Diagnosis between Fibreglass Group and Control Group

\begin{tabular}{|c|c|c|c|c|c|c|c|c|c|c|c|c|c|c|c|c|}
\hline \multirow{2}{*}{\multicolumn{2}{|c|}{$X_{s}^{w}$}} & & \multicolumn{2}{|c|}{1} & \multicolumn{2}{|c|}{$2 A$} & \multicolumn{2}{|c|}{$2 B a$} & \multicolumn{2}{|c|}{$2 B b$} & \multicolumn{2}{|c|}{$2 B c$} & \multicolumn{2}{|c|}{$2 B d$} & \multicolumn{2}{|c|}{ Total } \\
\hline & & & $F G$ & $C$ & $F G$ & $C$ & $F G$ & $C$ & $F G$ & $C$ & $F G$ & $C$ & $F G$ & $C$ & $F G$ & $C$ \\
\hline 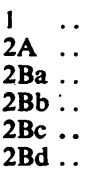 & $\begin{array}{l}\because \\
\because \\
\because \\
\because \\
.\end{array}$ & $\begin{array}{l}. \\
\ddot{y} \\
\therefore \\
. \\
.\end{array}$ & $\begin{array}{r}24 \\
5 \\
5 \\
3\end{array}$ & $\begin{array}{r}25 \\
6 \\
4 \\
8\end{array}$ & & & $\begin{array}{r}3 \\
11\end{array}$ & 6 & $\begin{array}{l}7 \\
1\end{array}$ & $\begin{array}{l}4 \\
1 \\
4 \\
4 \\
1\end{array}$ & $\begin{array}{l}4 \\
4 \\
2 \\
1\end{array}$ & 2 & & 1 & $\begin{array}{r}31 \\
20 \\
12 \\
6 \\
1\end{array}$ & $\begin{array}{r}13 \\
10 \\
12 \\
2\end{array}$ \\
\hline Total & 。 & .. & 37 & 43 & & & 14 & 6 & 8 & 14 & 11 & 4 & & 1 & 70. & 68 \\
\hline
\end{tabular}

FG = fibreglass group; $\mathbf{C}=$ control group

Radiologist W diagnosed significantly more glass fibre workers than control subjects as 'healed tuberculosis' or 'inflammatory' $\left(\chi^{2}=8.49\right.$ with 3 degrees of freedom; 0.05 $\left.>P>0.025\right)$.

There was no significant difference, however, between the glass fibre and control groups according to the diagnoses of radiologist $S\left(\chi^{2}=3.6\right.$ with 3 degrees of freedom; $\left.P=0.3\right)$.

TABLE 3

Agreed X-RAY Diagnoses

\begin{tabular}{|c|c|c|c|c|c|c|c|}
\hline & & 1 & $2 B a$ & $2 B b$ & $2 B c$ & $2 B d$ & Total \\
\hline $\begin{array}{l}\text { Fibreglass } \\
\text { Control . . }\end{array}$ & $\begin{array}{l}\cdots \\
\cdots\end{array}$ & $\begin{array}{l}24 \\
25\end{array}$ & $\begin{array}{r}11 \\
6\end{array}$ & $\begin{array}{l}7 \\
4\end{array}$ & $\begin{array}{l}7 \\
0\end{array}$ & $\begin{array}{l}0 \\
1\end{array}$ & $\begin{array}{l}44 \\
36\end{array}$ \\
\hline Total & .. & 49 & 17 & 11 & 2 & 1 & 80 \\
\hline
\end{tabular}

Between fibreglass workers and controls $\chi^{2}=1.87$ with 2 degrees of freedom; $P \simeq 0.4$.

Forty-five per cent. of glass fibre workers had suffered for a short period from 'new starter's glassfibre rash', and 12 glass fibre workers as opposed to 19 controls complained of phlegm. For phlegm a one-sided sign test gave a value for $z$ of $1 \cdot 83$, corresponding to a probability of 0.0336 . This showed that the control group had significantly more complaints at the $5 \%$ level (two-sided test gives a probability of 0.067 ).

It proved impossible to provide additional matching for smoking habits in view of the already stringent criteria for pairing, but analysis of the replies to the questionnaire shows no significant difference between the fibreglass and control groups either in the number of those who smoked or in the amount they admitted to smoking.

\section{Lung function}

Peak expiratory flow rate The observed reading was compared with the predicted rate derived for each subject by means of Cotes' (1968) formula for height and age (Table 4).

Comparison of the observed peak expiratory flow rate for each matched pair of subjects showed some

TABLE 4

LUNG FUNCTION STUDIES:

COMPARISON BETWEEN Fibreglass Workers AND CONTROLS

\begin{tabular}{|c|c|c|c|c|c|c|c|}
\hline \multirow{2}{*}{ Test } & & \multirow{2}{*}{ Observed } & \multirow{2}{*}{ Predicted } & \multicolumn{4}{|c|}{ Significance } \\
\hline & & & & Test & $\begin{array}{l}\text { Degrees of } \\
\text { freedom }\end{array}$ & $\begin{array}{l}\text { Mean square } \\
\text { ratio }\end{array}$ & Significance \\
\hline $\begin{array}{l}\text { PEFR } \\
\text { (70 pairs) }\end{array}$ & $\begin{array}{l}\text { Workers } \\
\text { Controls }\end{array}$ & $\begin{array}{l}470 \\
450\end{array}$ & $\begin{array}{l}519 \\
519\end{array}$ & $\begin{array}{c}\text { Between groups } \\
, \quad \text { pairs }\end{array}$ & $\begin{array}{r}1 \\
69\end{array}$ & $\begin{array}{l}1 \cdot 345 \\
1 \cdot 439\end{array}$ & $\begin{array}{l}\text { NS } \\
\text { NS }\end{array}$ \\
\hline $\begin{array}{l}\mathrm{FEV}_{1 \cdot 0} \\
(52 \text { pairs) }\end{array}$ & $\begin{array}{l}\text { Workers } \\
\text { Controls }\end{array}$ & $\begin{array}{l}2 \cdot 787 \\
2 \cdot 635\end{array}$ & $\begin{array}{l}2 \cdot 279 \\
2 \cdot 265\end{array}$ & $\begin{array}{c}\text { Between groups } \\
\quad, \quad \text { pairs }\end{array}$ & $\begin{array}{r}1 \\
51\end{array}$ & $\begin{array}{l}2 \cdot 2714 \\
3 \cdot 5329\end{array}$ & $\begin{array}{c}\mathrm{NS} \\
\text { At } 0.1 \% \text { level }\end{array}$ \\
\hline $\begin{array}{l}\text { FVC } \\
\text { (52 pairs) }\end{array}$ & $\begin{array}{l}\text { Workers } \\
\text { Controls }\end{array}$ & $\begin{array}{l}3 \cdot 819 \\
3 \cdot 596\end{array}$ & $\begin{array}{l}2.940 \\
2.944\end{array}$ & $\begin{array}{c}\text { Between groups } \\
\quad, \quad \text { pairs }\end{array}$ & $\begin{array}{r}1 \\
51\end{array}$ & $\begin{array}{l}5 \cdot 565 \\
6.096\end{array}$ & $\begin{array}{l}\text { At } 5 \% \text { level } \\
\text { At } 0.1 \% \text { level }\end{array}$ \\
\hline
\end{tabular}


large differences and as there were a substantial number of ties an analysis of variance was chosen to compare the groups. This showed no significant difference between groups or between pairs.

FEV $_{1 \cdot 0}$ and FVC Measurements were recorded with a Vitalograph and the predicted values were derived from the corresponding nomogram of Kory et al. (1961).

These investigations were made at an interval of approximately six months after the peak flow measurements, resulting in one or other member of 18 pairs seceding from the survey. Consideration of the difference in sample size, the distribution of those seceding, and the randomness of their reasons (left, transferred, sick, etc.) led us to conclude that the remaining sample size of 52 still constitutes a completely valid basis of comparison.

As the study is a comparative one and the ambient temperature of the room used fluctuated by only $2{ }^{\circ} \mathrm{C}$ temperature correction was ignored (Table 4).

Analysis of variance was again used and showed no significant difference between the fibreglass and control groups with respect to the $\mathrm{FEV}_{1.0}$ measured values. There was a difference, significant at the $5 \%$ level, however, between the FVC measured values to the disadvantage of the control group (the values for the fibreglass group being greater). This may be related to the small increase in the control group's complaints of phlegm. There was no significant difference between the two groups for predicted values of either $\mathrm{FEV}_{1 \cdot 0}$ or FVC at the $5 \%$ level.

\section{Discussion}

In the early days of glass fibre production the filaments tended to be larger and thicker and Gardner (1940) concluded that there were no adverse effects upon health due to inhalation because the fibres were too large to be respirable.

Expressing doubt about these conclusions, Schepers (1955) performed a series of inhalation studies with glass wool in animals, one presentation being of 6 microns diameter, which is very close to the types of glass fibre in manufacture for the last 15 to 20 years. He described endobronchiolar and peribronchiolar lesions with a 'tendency towards bronchial epithelial hyperplasia' and interstitial pneumonitis. No controls were used and the findings have already been criticized by Gross, Westrick, and McNerney (1960) for the lack of proof that the lesions were due to dust and not of spontaneous origin, as in his view such lesions occur spontaneously in stock animals with sufficient frequency to make proof mandatory.

In a further study in animals on 'fibreglass-plastic' dust (glass fibre sized with a phenolformaldehyde resin) Schepers et al. (1958) concluded that lesions characteristic of 'inert' dust were produced and observed that inhaled dust sporadically and mildly stimulated tuberculous infection, although this response was self-limiting in spite of continued dust exposure.

Intentionally high dust concentrations were used but unfortunately there was no indication given of how much was respirable.

Schepers speculated as to whether lesions similar to those he described might develop in plant operatives and be radiologically demonstrable and suggested that a careful watch be kept for an enhanced tuberculous response.

Some interest in the latter observation may be stimulated by reference to Table 1 which shows that of the small number of cases of healed tuberculosis reported in the present investigation approximately twice the number occurred in subjects as in the controls. The numbers are not statistically significant, but the small number of cases would make it unwise to draw any conclusions, and the observation, although interesting, must await further investigation. Only pre-existing chest conditions which might have been attributable to previous occupations were excluded from the survey.

The problem of assessing glass fibre as a pulmonary hazard was not much advanced by these studies, and it remained to Gross et al. (1960) to investigate the effect of glass dust independent of the plastic component.

In a well-controlled experiment Gross concluded that exposure to high concentrations of respirable glass dust for one year produced only minimal lesions in the guinea-pig, as did similar exposure of intratracheal injection in rats. The lesions consisted only of small focal alveolar dust cell collections without fibrosis.

In a personal communication to Konzen (1968) Gross is reported as finding a similar response to fibrous glass wool, phenolformaldehyde-sized glass fibre, and fibres with a starch coating.

The question of species response remains, as does that of the safety of long-term exposure to the dust concentrations met in industry.

Wright (1968), in the United States, reviewing periodical chest radiographs and medical records of a group employing 1401 employees with a minimum exposure of 10 years in glass fibre manufacturing, reported that 'no injurious pattern of radiological densities was observed' and concluded that 'the frequency of various radiological appearances known to occur in the general population was no higher in those with the grea:er exposure than in those with the least'.

The absence of a matched control group mitigates the argument, and the lack of information about dust levels diminishes its usefulness.

The same criticisms apply to a more recent study 
by Nasr, Ditchek, and Scholtens (1971), who considered that there was no difference in the prevalence of all (radiographic) abnormalities between office and production workers.

A search of the literature reveals a striking lack of reports of human pulmonary pathology. A case of an electrician presenting with haemoptysis was described by Murphy (1961), a localized lesion being found at lobectomy consisting of multiple focal abscesses arising from terminal bronchi and bronchioles and containing minute glass fibre particles. An earlier case associated with pneumonia was reported by Kahlau (1947). Dadashian (1969) has described five cases exposed to glass fibre dust in the textile industry, who suffered from asthmatic symptoms. None of these reports withstands critical evaluation and they underline the danger of too readily assuming that exposure to glass fibre, or the observation of it in the respiratory tract, necessarily implies a causal relationship with specific pathology.

The present study was undertaken to evaluate the significance of these experiments and clinical observations in a carefully matched control series and a working population with a lengthy exposure, against as clear a quantitative statement as possible of the level of exposure to respirable dust.

Matching has been achieved satisfactorily and the length of exposure is sufficient to indicate any risks of pneumoconiosis present. It might be contended that some selection in the subject population may have occurred due to susceptibles leaving their employment after early adverse symptoms. This sometimes occurs with skin irritation in the first few months of employment, but it is not our experience that there is undue wastage for reasons of health after the firs! few months.

The absence of knowledge of age and weight tended to maximize the reporting of radiographic minutiae by the radiologists, but in spite of this no significant difference was found between the controls and the subjects, a conclusion reinforced by the absence of any discernible pattern when the subjects' films were later reviewed, with this knowledge, as a group, and again in the independent review by Dr. Gilson.

Lung function tests and the results of the questionnaire similarly failed to show any evidence of pulmonary symptoms or diminished pulmonary function.

We would like to thank Dr. G. B. Scarrow and Dr. F. Wright for their assistance in reading the radiographs and Dr. J. C. Gilson for his kindness in reviewing the films and allowing us to publish his comments.

\section{References}

Cotes, J. C. (1968). Lung Function, 2nd ed., p. 375. Blackwell Scientific Publications, Oxford.

Dadashian, A. M. (1969). The role of fibreglass dust in the origin of bronchial asthma (translation). Vrachenoe Delo, 10, 87-89.

Gardner, L. U. (1940). Annual Report of the Saranac Laboratory for the Study of Tuberculosis of the Edward L. Trudeau Foundation, Saranac Lake, N.Y., pp. 8-11.

Gilson, J. C. Personal communication.

Gross, P., Westrick, M. L., and McNerney, J. M. (1960). Glass dust. A study of its biological effects. A.M.A. Archives of Industrial Health, 21, 10-23.

Hygiene Standards for Chrysotile Asbestos Dust (1968). From the Committee on Hygiene Standards of British Occupational Hygiene Society. Pergamon Press, Oxford.

Kahlau, G. (1947). Tödliche Pneumonie nach Glasstaubinhalation durch Verarbeitung eines Kunstoffes aus Glasswolle. Frankfurter Zeitschrift für Pathologie, 59, 143-150.

Konzen, J. L. (1968). Health of fibrous glass workers. Industrial Hygiene Foundation of America. Transactions Bulletin, 42, 101.

Kory, R. C., Callahan, R., Boren, H. G., and Syner, J. C. (1961). Clinical spirometry in normal men. American Journal of Medicine, 30, 243-258.

Medical Research Council (1960). Short Questionnaire on Respiratory Symptoms (approved by Medical Research Council Committee on Aetiology of Bronchitis).

Murphy, G. B. Jnr. (1961). Fiber glass pneumoconiosis. Archives of Environmental Health, 3, 704-710.

Nasr, A. N. M., Ditchek, T., and Scholtens, P. A. (1971). The prevalence of radiographic abnormalities in the chests of fiber glass workers. Journal of Occupational Medicine, 13, 371-376.

Schepers, G. W. H. (1955). The biological action of glass wool. A.M.A. Archives of Industrial Health, 12, 280-287.

Schepers, G. W. H., Durkan, T. M., Delahant, A. B., Redlin, A. J., Schmidt, J. G., Creedon, F. T., Jacobson, J. W., and Bailey, D. A. (1958). The biological action of fiberglas-plastic dust. A.M.A. Archives of Industrial Health, 18, 34-57.

Wright, G. W. (1968). Airborne fibrous glass particles. Archives of Environmental Health, 16, 175-181.

Received for publication November 9, 1971.

Accepted for publication November 2, 1972. 